\title{
Considerações sobre a (Re)Produção do Espaço Urbano Periférico de Curitiba: uma análise do discurso preliminar da Nova Lei de Zoneamento da metrópole
}

\author{
Considerations about the Production and Reproduction of the Peripheral Urban \\ Space in Curitiba: a preliminary discourse analysis of the metropolis' New Zoning \\ Law
}

Consideraciones sobre la Producción y Reproducción del Espacio Urbano Periférico de Curitiba: un análisis del discurso preliminar de la Nueva Ley de Zonificación de la metrópolis

\author{
Marina Roberta Padilha de Freitas ${ }^{1}$
}

Ricardo Peixoto ${ }^{2}$

\begin{abstract}
RESUMO: Por intermédio de uma superfície de toque entre Geografia Crítica e Linguística Aplicada, a proposta deste artigo é de refletir e tornar inteligíveis considerações preliminares a respeito de alguns dos elementos discursivos contidos na vinculação midiática da nova, e recém aprovada, Lei de Zoneamento, Uso e Ocupação do Solo de Curitiba (2019), em substituição à lei do ano de 2000. Para tanto, foi atentado também à relação desse instrumento urbanístico com a produção do espaço urbano periférico, a fim de estabelecer uma análise crítica que visa à compreensão dos significados desse discurso e de suas materializações. Para isso, recorreu-se à análise do discurso crítica enquanto base para a reflexão crítica da produção do espaço urbano periférico, sob o viés de entendimento de como este se produz e como se planificam, por meio do Estado, os "desígnios" urbanísticos do uso da terra. Entende-se, assim, com ajuda de pesquisadores que discutem a (re)produção do espaço urbano, a questão urbana, o planejamento, o discurso de poder e a linguagem, embutidos no instrumento de ordenamento territorial, que este segue a mesma lógica de estruturação do espaço que postula o coletivo sem, no entanto, contemplá-lo de fato quando à materialidade do discurso, pois, trata-se de um discurso ideológico.
\end{abstract}

PALAVRAS-CHAVE: Planejamento. Zoneamento urbano. Discurso. Ideologia. Performatividade.

\begin{abstract}
This article intends to reflect on and to clarify some considerations regarding a few discursive elements through an intersection between Critical Geography and Applied Linguistics. Such discursive elements are in the new and recently approved Zoning Law from the city of Curitiba (2019), State of Paraná, Brazil, which substituted the one published in 2000. In order to do so, it was also

\footnotetext{
${ }^{1}$ Programa de Pós-graduação em Geografia da Universidade Federal do Paraná. Rua Francisco H. dos Santos, n. 100, Jardim das Américas. Curitiba/PR. marinarpfreitas@gmail.com.

2 Programa de Pós-graduação em Letras da Universidade Federal do Paraná. Rua General Carneiro, n. 460, Centro. Curitiba/PR. rpeixoto431@gmail.com.
} 
considered the production of peripheral urban space aiming to establish a critical analysis which intends to comprehend the meanings of this discourse and its materialization. For this purpose, Critical Discourse Analysis served as basis to the critical reflection about peripheral urban space production, seeking to understand how the urban land use "design" is produced and how it is planned by the State. Therefore, it is understood that, with the help of researchers who discuss the production and reproduction of the urban space, the urban matter, the planning, the discourse of power, and language - inserted within the document of land use -, such document follows the same logic of space structuration that postulates the collective, however without considering it regarding discourse materiality, because it is an ideological discourse.

KEYWORDS:Planning. Urban zoning. Discourse. Ideology. Performativity.

RESUMEN: Este artículo pretende reflexionar y aclarar algunas consideraciones con respecto a algunos elementos discursivos a través de una intersección entre Geografía Crítica y Lingüística Aplicada. Tales elementos discursivos están en la nueva y recientemente aprobada Ley de Zonificación de la ciudad de Curitiba (2019), Estado del Paraná, Brasil, que sustituyó la ley de 2000. Para ello, también se consideró la producción del espacio urbano periférico con el objetivo de establecer un análisis crítico que pretenda comprender los significados de este discurso y su materialización. Para este propósito, el Análisis Crítico del Discurso sirvió como base para la reflexión crítica sobre la producción espacial periférica urbana, buscando comprender cómo se produce el "diseño" del uso del suelo urbano y cómo se planifica a través del Estado. Por lo tanto, se entiende que, con la ayuda de investigadores que discuten la producción y reproducción del espacio urbano, la materia urbana, la planificación, el discurso del poder y el lenguaje, insertado dentro del documento de uso de la tierra. Dicho documento sigue la misma lógica de estructuración del espacio que postula lo colectivo, sin embargo, sin considerarlo con respecto a la materialidad del discurso, porque es un discurso ideológico.

PALABRAS-CLAVE: Planificación. Zonificación urbana. Discurso. Ideología. Performatividad.

\section{INTRODUÇÃO}

O presente trabalho se insere no escopo de considerações realizadas no desenvolvimento da dissertação de mestrado da primeira autora e das investigações em Linguística Aplicada do segundo autor, estabelecendo uma superfície de toque entre duas áreas altamente interdisciplinares. Nesse sentido, haverá um intercâmbio entre Geografia Crítica e a análise do discurso crítica. Aqui são abordadas considerações a respeito da nova lei de zoneamento urbano que entrará em vigor no ano de 2020.

Há, no presente momento, uma "ordenação territorial" na metrópole, que estabelece o uso e a ocupação do solo de acordo com os eixos viários. Frisa-se, nesse sentido, que este ordenamento é estabelecido apenas para a metrópole, por meio de uma estruturação realizada pelo IPPUC (Instituto de Pesquisa e Planejamento Urbano de Curitiba). Entretanto, suas materializações são refletidas na região metropolitana por conta de um sistema de integração do transporte público, ou seja, tantos os eixos quanto o uso e ocupação do solo, nos parâmetros urbanísticos, são definidos conforme as projeções de organização da metrópole. Tais aspectos dizem respeito à lei de zoneamento estabelecida na década de 1975, que infere parâmetros diversos para a possibilidade de construção ou indicações para 
construção e uso, sejam habitacionais ou comerciais, sejam de áreas onde se deve garantir a preservação ambiental ou de uso restrito, entre outros.

O zoneamento urbano da e na metrópole de Curitiba, que tinha vigência do ano 2000 até o ano de 2019 (CURITIBA, 2000), orientou a discussão realizada sobre as possíveis projeções de ocupação habitacional na região periférica. Para fins de demonstração usarse-á o exemplo do bairro São Miguel, que, por ser adjacente à Cidade Industrial de Curitiba (CIC), é um bairro que recebe e se constrói conforme o que se estabelece tanto no zoneamento urbano quanto no que diz respeito aos movimentos de produção do espaço urbano da $\mathrm{CIC}$, bem como dos sujeitos de produção destes espaços. Isso dar-se-á pelo fato de que se entende que as análises necessitam partir de uma materialidade para que fujam a meras elucubrações teóricas, sem necessariamente aprofundar nas especificações sobre o bairro que não atendam à pretensão desse trabalho.

Para tanto, a pretensão deste trabalho está na proposta de identificação de quais aspectos dessa nova lei, publicada em 2019 e vigente a partir de 2020, entendida como um discurso ideológico, se constituem enquanto avanço ou retrocesso no planejamento urbano e regional da metrópole, visto que a linguagem institucional possui um aspecto performativo, ou seja, ela age na materialidade social ao ser enunciada (AUSTIN, 1962; FOUCAULT, 1996). Sendo assim, será focalizado neste trabalho a notícia do portal online da Prefeitura Municipal de Curitiba que anuncia a nova lei, uma vez que até a data da escritura deste texto a nova lei de zoneamento ainda não havia sido publicada em Diário Oficial, assim, focalizando na (re)produção do espaço urbano periférico, mais especificamente o do bairro São Miguel - seja em relação às novas formas de apropriação do espaço que se apresentam acentuados nesse bairro, seja na organização do que se considera enquanto planificado, instituído pelo Estado.

Procura-se, então, entender e problematizar, por meio da análise do discurso crítica, os aspectos que se modificam no planificado, principalmente no que diz respeito à alteração de áreas anteriormente designadas para habitação. De acordo com Butler (1997, p. 8, tradução nossa),

Nós fazemos coisas com a linguagem, produzimos efeitos com linguagem e fazemos coisas para a linguagem, mas linguagem também é a coisa que fazemos. Linguagem é um nome para o nosso fazer: ambos 'o que' fazemos (o nome para a ação que nós performamos caracteristicamente) e aquilo do que somos efeito, $\mathrm{o}$ ato e suas consequências. ${ }^{3}$

\footnotetext{
${ }^{3}$ We do things with language, produce effects with language, and we do things to language, but language is also the thing we do. Language is a name for our doing: both "what" we do (the name for the action that we characteristically perform) and that which we effect, the act and its consequences.
} 
Por esse motivo, busca-se compreender aqui, numa interseção entre essas duas disciplinas, como o aspecto performativo da linguagem, no seu processo de produção discursiva, opera no discurso institucional da Prefeitura Municipal de Curitiba. Focaliza-se, assim, o instrumento urbanístico que entrará em vigência em contraposição ao ainda vigente: Lei de Zoneamento Uso e Ocupação do Solo de Curitiba, à luz dos processos decorrentes da "urbanização acelerada" das últimas décadas, no que diz respeito à reformulação de estratégias de valorização do espaço urbano, que, por sua vez, favorecem outros movimentos como a segregação socioespacial.

Hipoteticamente, mesmo com a reestruturação dos parâmetros de zoneamento urbano, alguns aspectos podem favorecer a ação de determinados grupos que já se beneficiam daquilo que é planificado em detrimento do "bem comum", reforçando o modelo já existente de planejamento pautado em uma lógica capitalista de (re)produção do espaço, de modo que se tornam questionáveis as intencionalidades presentes no novo documento. Isso se dá principalmente no que diz respeito a uma cidade que historicamente expulsa a sua pobreza para as margens ou as esconde atrás de grandes obras urbanísticas.

Para tanto, desenvolveu-se uma tática reflexiva argumentativa, informada pela Análise do Discurso Crítica - visto que essa área do saber percebe a linguagem com prática social, propondo um debate teórico e metodológico para contribuir com a compreensão de dilemas contemporâneos (MAGALHÃES, 2005) -, com base na análise do documento de planejamento anterior e o discurso atual, a fim de compreender os aspectos mais significativos e relevantes para estas considerações. Infere-se, assim, que as intencionalidades permanecem sendo fomentadas conforme os interesses de poucos sob a tarja e fachada de um instrumento de organização que prioriza o coletivo.

\section{DESENVOLVIMENTO}

Minimizar os problemas decorrentes da urbanização é um dos principais esteios de fundamentação do planejamento urbano e regional. A rápida urbanização nacional gerou um descompasso no que diz respeito às diferentes formas de apropriação do espaço e o que é planificado pelo Estado. Esse descompasso, entre as necessidades da população segregada, da população média e dos sujeitos detentores de poder - sejam os agentes imobiliários, grandes detentores de terra, seja o Estado - gera demandas sociais, pois amplifica os processos de segregação que, em diferentes instâncias, diminuem a qualidade de vida. É possível, portanto, alinhar-se com o posicionamento de Volóshinov (2018, p. 110111) que afirma que: 
Em cada etapa do desenvolvimento social existe um conjunto específico e limitado de objetos que, ao chamarem a atenção da sociedade, recebem uma ênfase valorativa. Apenas esse conjunto de objetos obterá uma forma sígnica, isto é, será objeto da comunicação sígnica. O que então determina esse conjunto de objetos que são enfatizados valorativamente? Para que um objeto, independentemente do tipo da sua realidade, entre no horizonte social de um grupo e provoque uma reação ideológica sígnica, é necessário que ele esteja relacionado com as premissas socioeconômicas essenciais da existência desse grupo; é necessário que, de algum modo, ele toque, mesmo que parcialmente, as bases da existência material desse grupo.

Dessa forma, o planejamento urbano em sua forma documental, possui uma ênfase valorativa que estabelece ações sobre a realidade social, ao mesmo tempo em que gera demandas no que diz respeito à projeção de ações a serem realizadas. Essa ênfase valorativa, portanto, constitui-se pelo conjunto de interesses e de valores de um determinado grupo social e está sempre em processo de formação e transformação (VOLÓSHINOV, 2018).

Nesse mesmo caminho, para Souza, Oliveira e Santos (2019), houve uma explosão de novas formas de urbanismos, que surgiram em decorrência a crise de 2008 e se acentuaram a partir de 2014. Esse processo exigiu novas respostas às demandas urbanas emergentes, mudanças de estratégias e de escala, bem como o aprofundamento das perspectivas de análise, assumindo-se uma posição crítica sobre o assunto.

O documento de planejamento urbano se caracteriza, então, enquanto discurso regulatório daquilo que é possível ser materializado no espaço urbano, ou que se almeja materializar. Ainda de acordo Souza, Oliveira e Santos (2019, p. 20), no que diz respeito ao planejamento urbano:

[...] o conceito de planejamento urbano extrapola as delimitações específicas de urbanismo, e contempla diversas áreas do conhecimento pertinentes à construção das cidades e suas conexões, tais como economia, sociologia, antropologia, geografia, entre muitos outros conhecimentos. Portanto, é importante ressaltar que o planejamento urbano compreende um projeto abrangente de cidade e região, com uma abordagem multidisciplinar, diferente do foco morfológico, específico do urbanismo.

Nesse sentido, ressalta-se que compreender o planejamento urbano e as suas possíveis materializações no espaço é essencial não apenas à reflexão crítica do assunto, mas também porque o planejamento é parte que coexiste ao urbanismo, ao estudo do urbano, ou seja, há um alinhamento direto na medida em que um passa a ser necessário ao ordenamento do outro, de forma dialógica. Entende-se que há uma racionalização no planejamento, que, em teoria, deve ser voltada ao enfrentamento das desigualdades socioeconômicas e à solução do descompasso da rápida urbanização. 
Em concomitância, a realidade não "obedece" necessariamente à lógica de (re)produção do espaço enquanto planificado, de modo que as formas de apropriação do espaço diferem de acordo com as necessidades dos indivíduos e de onde eles se encaixam nas escalas e níveis econômicos no sistema de (re)produção capitalista do espaço, estando em posição de maior ou menor segregação. Sendo assim, é possível pensar em:

\begin{abstract}
[...] quando Foucault ressalta a agonística como se manifestando 'em um ambiente político-social propício a seu exercício, caracterizado como o confronto entre forças livres', recusa[ndo] a visão de poder como um sistema absoluto de dominação, não permitindo espaços para resistência. Ou seja, Foucault ressalta que o poder não controla tudo, e há sempre lugar para a prática da liberdade. Significa dizer que onde se exerce poder, existem práticas de resistência (SEIXAS, 2013, s/p.).
\end{abstract}

Para Rodrigues (2007), a desigualdade na apropriação do espaço se exterioriza nos modos de apropriação da mercadoria da terra, da exploração e da espoliação da força de trabalho, da acumulação desigual no espaço e da presença paradoxal do Estado. Este último, no entanto, é responsável por acentuar as condições inerentes ao modo de produção capitalista e produzir espaços de segregação.

A produção desigual do espaço requer, para sua compreensão, que se identifiquem as contradições na complexidade de sua produção, o que nos encaminha à reflexão de sobre o modo como se dá a apropriação de terras sob a lógica do mercado imobiliário e dos proprietários de terrenos. Contudo, apesar de isso não ser o foco desse trabalho, é importante ressaltar que, conforme afirmou Rodrigues (2007), o valor da reprodução do espaço urbano evidencia a segregação socioespacial, que engloba as áreas produzidas pelos trabalhadores e a expansão, ou surgimento, das áreas nobres e esses aspectos em alguma instância são fomentados também pelas ações do Estado por meio de seus instrumentos.

Sendo assim, o Estado atua em uma aparente "não ação" seja no enfrentamento ativo de fenômenos como especulação imobiliária e segregação socioespacial (dados dispendiosos e longos processos de regularização fundiária urbana, por exemplo), seja na aplicação de instrumentos legais no intuito de reduzir danos colaterais e em seus modos de ação e regulação. Há sempre um fortalecimento em diversas ações que nem sempre representam os interesses do coletivo.

\title{
RESULTADOS E DISCUSSÕES
}

Para Amaral (2017), o que se observa em relação à política urbana realizada pelo Estado é que há uma subordinação aos imperativos monopolistas, que geram uma desproporção no financiamento entre setores que estão diretamente ligados à geração de 
mais valia. Sendo assim, o Estado entra na produção urbana com o financiamento público de itens que podem vir a ser rentáveis para os capitalistas, havendo, dessa maneira, a criação de condições privilegiadas a diferentes sujeitos. Pois, de acordo com Foucault (1998, p. 250), "Na medida em que as relações de poder são uma relação desigual e relativamente estabilizada de forças, é evidente que isto implica um em cima e um em baixo, uma diferença de potencial".

É importante destacar que, diante do objetivo deste trabalho, a análise da Lei de Zoneamento não se refere à uma análise textual descontextualizada, mas se propõe a "[...] destacar o modo de funcionamento da linguagem, sem esquecer que esse funcionamento não é integralmente linguístico, uma vez que dele fazem parte as condições de produção" (ORLANDI, 1987, p. 117). Ou seja, nesse processo analítico é necessário situar os protagonistas e o objeto do discurso, que, para os fins dessa produção, se referem aos sujeitos e à (re)produção do espaço urbano, respectivamente.

Nesse sentido, isso explicita a ênfase multidirecional implicada em tal processo, o de (re)produção do espaço urbano, a partir da interação de interesses de diferentes sujeitos. Para tanto, o pensamento de Volóshinov (2018) permite estabelecer as bases ideológicas da Lei de Zoneamento Urbano da metrópole de Curitiba - destacando que a Lei de Zoneamento estabelece eixos de integração entre a metrópole e a região metropolitana sem entretanto orientar o uso e ocupação do solo da região metropolitana -, pois estabelece um cruzamento de ênfases multidirecionais orientadas ideologicamente. Nas palavras do autor:

A existência não apenas é refletida no signo, mas também é refratada nele. O que determina a refração da existência no signo ideológico? - O cruzamento de interesses sociais multidirecionados nos limites de uma coletividade sígnica, isto é, a luta de classes. A classe não coincide com a coletividade sígnica, ou seja, com a coletividade que utiliza os mesmos signos da comunicação ideológica. Por exemplo, várias classes podem utilizar a mesma língua. Em decorrência disso, em todo signo ideológico cruzam-se ênfases multidirecionadas. O signo transforma-se no palco da luta de classes (VOLÓSHINOV, 2018, p. 112-113).

Tendo em vista as consequências geradas pelo processo de planificação imposta pelo Estado ao produzir um documento tal como a Lei de Zoneamento, é necessário, então, debruçar-se sobre o discurso que é produzido. Entende-se aqui que discurso não é apenas "[...] um encadeamento lógico de frases e palavras que pretendem um significado em si, mas, antes, ele se colocará como um importante instrumento de organização funcional que pretende estruturar determinado imaginário social" (BRANDÃO, 2015, p. 392).

Desse modo, ao apreender que lógicas de funcionamento discursivo são mobilizadas na Lei de Zoneamento, pode-se inferir que matrizes de inteligibilidade são produzidas a respeito do espaço urbano, sua produção e reprodução, pois "[...] em um discurso, então, 
não só se representam os interlocutores, mas também a relação que eles mantêm com a formação ideológica. E isto está marcado no e pelo funcionamento discursivo" (ORLANDI, 1987, p. 125).

O Estado dispõe de instrumentos criados com o intuito de ordenar o espaço urbano, ordenamento este que causa maior ou menor tensão de acordo com os interesses dos grupos sociais que disputam determinado território. Entende-se que a terra urbana, a habitação, a circulação e o comércio envolvem inúmeros agentes sociais, com ou sem capital, o que tensiona a produção do espaço de diferentes modos. Nesse sentido, é impossível não lembrar de Foucault (1998, p. 75) ao afirmar que "[...] [o]nde há poder, ele se exerce. Ninguém é, propriamente falando, seu titular; e, no entanto, ele sempre se exerce em determinada direção, com uns de um lado e outros do outro; não se sabe ao certo quem o detém; mas se sabe quem não o possui". Sendo assim, é esta (e nesta) a tensão/contradição que marca a ação do Estado no urbano, capaz de produzir o entendimento de que sua ação se realiza como uma espécie de mediadora de conflitos sobre a terra na cidade.

Para os fins deste trabalho, o acesso às informações a respeito das modificações em relação à Lei de Zoneamento Urbano de Curitiba deu-se pelo site da Prefeitura Municipal de Curitiba (CURITIBA, 2019), visto que o texto, na data da escritura deste trabalho, ainda não tinha sido publicado. Contudo, como a proposta aqui apresentada é de uma análise de discurso e não de conteúdo textual, é possível apreender os regimes de verdade que se constroem por meio da notícia que divulga as informações no site da prefeitura.

Nesse sentido, compreende-se que o posicionamento apresentado no site oficial da prefeitura supõe um discurso de poder, criando, assim, um regime de verdade a respeito da nova lei. Nas palavras de Foucault (1998, p. 12):

\begin{abstract}
A verdade é deste mundo; ela é produzida nele graças a múltiplas coerções e nele produz efeitos regulamentados de poder. Cada sociedade tem seu regime de verdade, sua 'política geral' de verdade: isto é, os tipos de discurso que ela acolhe e faz funcionar como verdadeiros; os mecanismos e as instâncias que permitem distinguir os enunciados verdadeiros dos falsos, a maneira como se sanciona uns e outros; as técnicas e os procedimentos que são valorizados para a obtenção da verdade; o estatuto daqueles que têm o encargo de dizer o que funciona como verdadeiro.
\end{abstract}

Lembrando-se, desse modo, que "[...] [a] análise do enunciado não pode ser feita dentro dos limites da linguística do sistema: aquela tendência de pensamento linguístico que, por meio de uma abstração, isola a forma linguística do enunciado" (VOLÓCHINOV, 2018, p. 257-258), mas que o enunciado deve ser entendido como "[...] um elo na cadeia da comunicação discursiva e um elemento indissociável das diversas esferas ideológicas" (VOLÓCHINOV, 2018, p. 257). E, baseando-se, ainda, no pensamento foucaultiano exposto 
acima, é possível apreender que o discurso veiculado pela prefeitura, na notícia de divulgação com os detalhes sobre a nova Lei de Zoneamento, Uso e Ocupação do Solo de Curitiba, foi construído como "[...] uma lei democrática e que vai encaminhar o futuro de Curitiba gerando emprego, renda e melhorando a habitação dos curitibanos" (CURITIBA, 2019).

Para produção do espaço urbano é necessário que se recorte o tempo-espaço de análise, a fim de permitir que se interprete as diferentes escalas, contextos históricos e agentes econômicos sociais políticos. Da mesma maneira, para compreender a produção do espaço urbano periférico e as implicações na nova Lei de Zoneamento Urbano se faz necessário estabelecer recortes, pois há uma vasta discussão entre diversos fenômenos urbanos, por exemplo, aqueles que se dão na/pela dinâmica centro-periferia.

Nesse sentido, à exemplo, um dos pontos frisados na nova Lei diz respeito a "[...] priorização do uso não habitacional nas pontas dos Eixos Estruturais Norte e Sul como estímulo à geração de empregos nessas áreas, contribuindo para o reequilíbrio das demandas em transporte coletivo nas vias expressas" (CURITIBA, 2019). Desse modo, o que se identifica em ambos os documentos, o vigente e o discurso do reestruturado, é que o primeiro pouco sinaliza elementos que dizem respeito aos espaços destinados à habitação, e outro modifica ou dá luz ao almejo de novas zonas de interesse social, com intuito de priorizar o adensamento populacional no centro e incentivar o comércio, no que é construído discursivamente no texto como "[...] estímulo à geração de empregos nessas áreas, contribuindo para o reequilíbrio das demandas em transporte coletivo nas vias expressas" (CURITIBA, 2019). Em teoria o:

[...] processo se dará pela oferta de coeficiente de aproveitamento diferenciado, acompanhado de estímulos à entrada no mercado de terrenos vazios com a aplicação de mecanismos específicos como a declaração de subutilização da área e a aplicação de IPTU Progressivo (CURITIBA, 2019).

Nesse aspecto ressalta-se o exemplo utilizado anteriormente nesta análise, o Bairro São Miguel, que é identificado no decorrer do desenvolvimento de uma das pesquisas, na qual este recorte se insere. O bairro se localiza em uma região adjacente ao eixo Sul do sistema viário e apresenta características de transição no que se pode considerar enquanto uma área de fronteira urbana, com um número significativo de projetos de loteamento, que, de acordo com os dados disponíveis no Mapa Cadastral do IPPUC (CURITIBA, 2018), são essencialmente com finalidade habitacional, mesmo que não de interesse social.

O discurso, salientado no trecho recortado nessa análise, infere ainda a entrada de "terrenos vazios" no mercado imobiliário, e, nesse sentido, não se pretende nesse momento realizar uma conjuntura teórica que explicite as questões conceituais a serem consideradas 
quando se trata da utilização da palavra "vazio", entretanto, a inserção de lotes com baixo coeficiente de utilização no mercado imobiliário não necessariamente favorece uma parcela significativa da sociedade que não possui condições de se inserir no mercado formal de habitação. Desse modo, cria-se um problema a ser analisado, qual seja: a existência na argumentação de uma priorização habitacional para o centro e a sinalização de áreas que outrora seriam destinadas a moradia, ainda que distantes, para finalidades comerciais.

Nesse sentido, questiona-se: que sujeitos, no contexto de (re)produção do espaço urbano consolidado e periférico, essa reestruturação do planejamento urbano está favorecendo? Pois, de acordo com Foucault (1998, p. 284), "[...] no caso da teoria do governo não se trata de impor uma lei aos homens, mas de dispor as coisas, isto é, utilizar mais táticas do que leis, ou utilizar ao máximo as leis como táticas. Fazer, por vários meios, com que determinados fins possam ser atingidos". Sendo assim, ao se analisar o discurso em torno da nova lei, infere-se que esta priorização ainda obedece a lógica capitalista de produção do espaço, ainda segue os moldes tradicionais que a metrópole de Curitiba estabelece, enquanto "citymarketing", ou cidade modelo, que repetidamente desvincula da sua imagem as dificuldades em tratar da segregação socioespacial e por intermédio de seus instrumentos legais não só as mantém, como fortalece.

Rémy (2005), quando trata do preço da terra, sinaliza as diferenças em relação às áreas próximas ao centro e as mais periféricas, no que diz respeito à disputa pelo espaço. Salienta ainda que o valor do solo não reside em um único elemento e que incorpora custos de planejamento e de transformação, de modo a converter-se num custo fundiário que determina os fatores de conflito espacial:

Tendo em consideração que as cidades podem apresentar formas mais ou menos policêntricas, a competição pelo uso do solo central é ainda o fator fundamental que determina a propriedade, a estrutura social, o uso, a densidade e, por conseguinte, os modelos e o aspecto do construído (RÉMY, 2005, p. 38).

No que diz respeito à apropriação do espaço, Carlos (2007) reflete que se colocam inúmeras possibilidades, isto porque o homem habita e se apropria dos espaços que habita, explorando o que a autora cita como o possível, de modo que a apropriação tem qualidades específicas que se relacionam com outros lugares. Entretanto, a apropriação e a dominação entram em conflito, estando a dominação no âmbito das estratégias que produzem o espaço da coação uma vez que o plano da política é normatizado e esta ordem é imposta à sociedade de modo a direcionar a prática social - e estando a apropriação na prática criativa contraria a norma.

Os espaços urbanos são permeados de diversos conflitos. Há uma tendência na acentuação da segregação de todas as formas cabíveis e passíveis de conceituação. 
Maricato (2001) afirma que a extensão das periferias urbanas tem sua expressão mais concreta na segregação espacial ou ambiental, com expressiva homogeneização da pobreza diante do aumento do processo de urbanização, de modo que entende-se que as questões relativas ao processo de urbanização são inúmeras e torna-se problemática a promoção da segregação a partir do Estado.

Entende-se, então, que a produção do espaço é resultante das ações da sociedade por meio de um conjunto de relações que, em maior ou menor medida, delineiam e definem a própria sociedade por diferentes formas de apropriação. Essas formas de apropriação dependem de vários elementos, inclusive os naturais, mas principalmente os relativos às construções ideológicas, às construções normativas do Estado e à atuação dos diferentes tipos de capital, sendo que a propriedade privada do solo também é reflexo das profundas desigualdades advindas do processo de produção do espaço.

Advoga-se, portanto, tendo em vista os apontamentos de Foucault (1998) e Volóchinov (2018) que não há quaisquer construções discursivas que não estejam imbuídas de intencionalidade ou ideologia. Sendo assim, recorre-se à Althusser (1996, p. 108) para salientar que ao, mesmo tempo que a reprodução da força de trabalho, a lógica capitalista também requer a:

[...] submissão às regras de ordem estabelecida, isto é, uma reprodução de sua submissão à ideologia vigente, para os trabalhadores, e uma reprodução da capacidade de manipular corretamente a ideologia dominante, para os agentes da exploração e da repressão, a fim de que também eles assegurem 'com palavras' a dominação da classe dominante.

A partir do pensamento althusseriano, apoia-se a asserção de que a Lei de Zoneamento, Uso e Ocupação do Solo de Curitiba opera com um viés ideológico, visando a manutenção da ocupação do espaço urbano da cidade sob a ótica da lógica capitalista. Cria-se, assim, um sistema ideológico que baseia o uso do solo da metrópole. Salienta-se, segundo Volóchinov (2018, p. 213), que:

Os sistemas ideológicos formados cristalizam-se a partir da ideologia do cotidiano e, por sua vez, exercem sobre ela uma forte influência inversa e costumam dar-lhe o tom. Todavia, ao mesmo tempo, esses produtos ideológicos formados preservam constantemente a mais viva ligação orgânica com a ideologia do cotidiano, nutrem-se da sua seiva e fora dela estão mortos, assim como estão mortas uma obra literária finalizada ou uma ideia cognitiva fora da sua percepção avaliativa viva.

O documento, portanto, sustenta discursivamente a ideologia imposta pelo Estado, criando um sistema ideológico que normaliza e normatiza o zoneamento da cidade. Dessa forma, pode-se assumir que a lei em questão, tanto em sua formulação vigente quanto à 
reformulação que entrará em vigência no ano de 2020, constitui-se enquanto uma obra ideológica do Estado. Entendendo que:

[...] uma obra ideológica existe apenas para essa percepção que se realiza na linguagem da ideologia do cotidiano. A ideologia do cotidiano insere a obra em uma dada situação social. A obra passa a ser ligada a todo o conteúdo da consciência e é percebida apenas no contexto dessa consciência atual. A obra é interpretada no espírito desse conteúdo da consciência (da consciência daquele que percebe) e é elucidada por ele de modo novo. É essa a vida de uma obra ideológica. Em cada época de sua existência histórica, a obra deve interagir estreitamente com a ideologia do cotidiano em transformação, preencher-se por ela e nutrir-se de sua seiva nova. Apenas à medida que a obra é capaz de interligar-se ininterrupta e organicamente com a ideologia do cotidiano de uma época, ela é capaz de ser viva dentro dela (é claro, em um dado grupo social). Fora dessa ligação, ela deixa de existir, por não ser vivida como algo ideologicamente significativo (VOLÓSHINOV, 2018, p. 213-214).

Nesse sentido, buscou-se sintetizar aqui as perspectivas que podem ser inferidas a partir de uma análise do discurso preliminar aqui realizada, cientes de que uma simplificação pode representar apenas as perspectivas que contemplem o que se foca na discussão e não na complexidade da produção do espaço urbano. Cabe ressaltar que a produção da metrópole, do seu espaço urbano periférico e dos conflitos que surgem nessa produção, de acordo com os moldes da metrópole, ou no intuito de mantê-la em funcionamento, se dão efetivamente por meio de normas, que podem ser entendidas como obras ideológicas, ou na quebra dessas normas. Sendo assim, a quebra das normas é um fator que gera conflitos, sempre inseridos dentro de uma rede de relações de poder entre os sujeitos que produzem o espaço urbano, e o Estado atua como instrumentador das normas e leis de regulação do uso do solo numa tendência homogeneizante.

\section{CONSIDERAÇÕES FINAIS}

Dada a análise preliminar do discurso, enquanto caminho reflexivo, do novo planejamento e da então afixada lei de zoneamento vigente, cabe ressaltar que a priorização de ação do planificado nos eixos viários implica no que pode ser entendido em sua finalidade como a amplificação renda da diferenciação dos espaços, ou seja, alguns dos aspectos como a mudança dos setores especiais de habitação de interesse social e as áreas que se priorizam para fins comerciais implicam em um processo de valorização da terra. Esse processo, essencial para a lógica capitalista, é negativo quando o instrumento em teoria deveria ser direcionado à redução das desigualdades socioespaciais. Nesse sentido, é importante perceber que, discursivamente, o posicionamento do Estado é o de 
apresentar o novo planejamento como democrático e facilitador da ideia de desenvolvimento.

Desse modo, no intuito reflexivo do presente momento, infere-se que há que se ultrapassar a ideia de que o Estado por si e as políticas públicas, que predizem uma homogeneização do espaço, são capazes de reduzir as mazelas sociais, pois nenhum discurso é neutro, e a Lei de Zoneamento, Uso e Ocupação do Solo de Curitiba não é exceção, servindo como uma obra ideológica do posicionamento do Estado. Observa-se, assim, por meio do discurso veiculado pela prefeitura, que os investimentos criam ciclos que perpetuam os movimentos de valorização e revalorização de áreas e, consequentemente, segregam uma parcela da sociedade, usando-se da lei em questão como uma tática para impor seus interesses inseridos na lógica capitalista de produção do espaço. Essa assertiva é feita sem, contudo, deixar de pontuar a necessidade da presença do Estado, pois, apesar de seu papel dúbio, ele é o sujeito que age mais diretamente sobre a produção do espaço.

Cabe ressaltar, ainda, que não se pode criar a ideia utópica de que a iniciativa privada, por exemplo, pode tomar as decisões sobre o ordenamento territorial - esta concepção não deixa de ser, também, ideológica em seu discurso. Pois, ao fazê-lo, tende-se a tomar os interesses individuais como universais, o que se debate bastante no que diz respeito ao poder absoluto da propriedade da terra e suas contradições, bem como no que diz respeito ao direito à cidade. Nesse sentido, pontua-se, ainda, que há de ser necessária a força popular, por meio da produção do espaço e apropriação na forma de permanência e resistência, para que se sobressalte o interesse público. Essa necessidade é decorrente de que o ideário vidente na construção ideológica do "mainstream" é a imagem de Curitiba enquanto uma cidade modelo.

Portanto, o diálogo interdisciplinar entre a Geografia Crítica e a Linguística Aplicada se mostrou como uma experiência produtiva para analisar o discurso, enquanto uma prática social performativa, que permeia a (re)produção do espaço urbano. Desse modo, superfície de toque entre essas disciplinas favorece criar pontes entre saberes que refletem sobre a realidade social, não procurando esgotar qualquer discussão, mas lançar olhares outros que explicitem a complexidade intrínseca à cidade.

\section{REFERÊNCIAS}

ALTHUSSER, L. Ideologia e aparelhos ideológicos de Estado (notas para uma investigação). In: ŽlŽEK, S. Um mapa da ideologia. Rio de Janeiro: Contraponto, 1996. p. 105-142.

AMARAL, R. D. O Estado: resgate teórico e reflexões contemporâneas. In: ENANPUR, 17., 2017, São Paulo. Anais [...]. São Paulo, 2017. p. 1-16. Disponível em:

http://anpur.org.br/xviienanpur/principal/?page_id=1360. Acesso em: 23 nov. 2019. 
AUSTIN, J. L. How to do things with words. Oxford: The Clarendon Press, 1962.

BRANDÃO, R. T. P. Resenha: a ordem do discurso. InterEspaço: Revista de Geografia e Interdisciplinariedade, Grajaú, v. 1, n. 3, p. 392-398, 2015.

BUTLER, J. Excitable speech: a politics of the performative. New York: Routledge, 1997.

CARLOS, A. F. A. O espaço urbano: novos escritos sobre a cidade. São Paulo: Contexto, 2007.

CURITIBA. Lei no 9800, de 3 de janeiro de 2000. Dispõe sobre o zoneamento, uso e ocupação do solo no município de Curitiba, revoga as leis no $4199 / 72,5234 / 75,5263 / 75$, 5490/76, 6204/81, 6769/85, 7068/87 e 7622/91, e dá outras providências. Curitiba: Câmara Minicipal, 2000. Disponível em: encurtador.com.br/egsPW. Acesso em: 15 ago. 2019.

CURITIBA. Mapa cadastral. Curitiba: Instituto de Pesquisa e Planejamento Urbano de Curitiba, 2018. Disponível em: http://ippuc.org.br/mapasinterativos/localizador/default.html. Acesso em: 1 fev. 2019.

CURITIBA. Nova lei de zoneamento na Câmara. Curitiba, 2019. Disponível em: https://www.curitiba.pr.gov.br/noticias/nova-lei-de-zoneamento-e-aprovada-nacamara/52657. Acesso em: 20 nov. 2019.

FOUCAULT, M. A ordem do discurso. São Paulo: Loyola, 1996.

FOUCAULT, M. Microfísica do poder. Rio de Janeiro: Graal, 1998.

MAGALHÃES, I. Introdução: a análise de discurso crítica. DELTA, São Paulo, v. 21, p. 1-9, 2005. Número especial.

MARICATO, E. Brasil, cidades: alternativas para a crise urbana. Petrópolis: Vozes, 2001.

ORLANDI, E. P. A linguagem e seu funcionamento: as formas do discurso. Campinas: Pontes, 1987.

RÉMY, A. Morphologie urbaine geographie: aménagement et architecture de la ville. Paris: Armand Colin, 2005.

RODRIGUES, A. M. Desigualdades socioespaciais: a luta pelo direito à Cidade. Cidades, Rio Claro, v. 4, n. 6, p. 73-88, 2007.

SEIXAS, R. L. R. Michel Foucault: a condição agonística entre o poder e a liberdade. In: BARROS, T. M. S.; SAMPAIO, J. L. (org.). Filosofia. Rio de Janeiro: MAUAD, 2013. s/p.

SOUZA, F. A. S.; OLIVEIRA, C. C. D.; SANTOS, P. A. A. A experiência recente do urbanismo e suas perspectivas. In: MARTINS, B. C. (org.). Planejamento urbano e regional. Ponta Grossa: Atena, 2019. p. 18-28.

VOLÓSHINOV, V. Marxismo e filosofia da linguagem: problemas fundamentais do método sociológico na ciência da linguagem. São Paulo: Ed. 34, 2018.

Recebido: novembro de 2019.

Aceito: abril de 2020. 